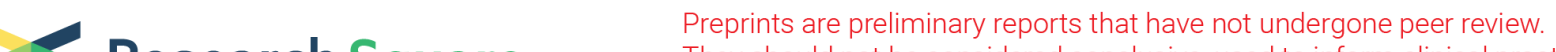 $\begin{array}{ll}\text { Research Square } & \text { They should not be considered conclusive, used to inform clinical practice, } \\ \text { or referenced by the media as validated information. }\end{array}$
}

\section{Levels of serum VEGF-C/D and CXCL-12 are related to the severity of proteinuria in diabetic nephropathy}

Qingshan Tian

First Affiliated Hospital of Nanchang University

\section{Zhichao Yang}

Jiujang No 1 Peoples Hospital: Affiliated Jiujiang Hospital of Nanchang University

Lianfei Li

First Affiliated Hospital of Nanchang University

Yun Kong

First Affiliated Hospital of Nanchang University

Hongwen Zhu

First Affiliated Hospital of Nanchang University

Yiheng Yang

First Affiliated Hospital of Nanchang University

Hao Wu

Boston Children's Hospital

Zhenzhong Zheng ( $\nabla$ zzz567890123@sina.com )

Nanchang University https://orcid.org/0000-0002-1730-8138

\section{Research}

Keywords: Type 2 diabetic nephropathy, VEGF-C, VEGF-D, CXCL-12

Posted Date: April 19th, 2021

DOI: https://doi.org/10.21203/rs.3.rs-426669/v1

License: (c) (i) This work is licensed under a Creative Commons Attribution 4.0 International License.

Read Full License 


\section{Abstract \\ Objective}

To investigate the relationship between serum levels of lymphangiogenic factors and type 2 diabetic nephropathy and to evaluate the role of lymphangiogenesis in diabetic nephropathy.

\section{Methods}

The patients were divided into a normal albuminuria group (UmAlb $<30 \mathrm{mg} / 24 \mathrm{~h}, \mathrm{n}=30$ ), microalbuminuria group (UmAlb $30-300 \mathrm{mg} / 24 \mathrm{~h}, \mathrm{n}=30$ ) and massive albuminuria group (UmAlb $>300$ $\mathrm{mg} / 24 \mathrm{~h}, \mathrm{n}=30)$, and 30 healthy individuals were enrolled as the healthy control group $(n=30)$. Levels of serum vascular endothelial growth factor-C (VEGF-C), vascular endothelial growth factor-D (VEGF-D) and chemokine ligand 12 (CXCL-12) were quantified by enzyme-linked immunosorbent assay kits.

\section{Results}

The serum levels of VEGF-C,VEGF-D and CXCL-12 were significantly increased in all type 2 diabetic nephropathy groups. The correlation analysis showed that serum levels of VEGF-C, VEGF-D and CXCL-12 were positively correlated with serum creatinine and urinary microalbumin, and negatively correlated with estimated glomerular filtration rate. For discriminating the DN patients in the massive albuminuria group, microalbuminuria group and normal albuminuria group, the areas under the receiver operating characteristic curve (AUC-ROCs) for VEGF-C were 0.668 (95\%Cl: $0.531-0.805)$, 0.799 (95\%Cl: $0.678-$ 0.920 ), and 0.850 (95\% Cl: $0.756-0.944)$; when the cutoff values were $152.40,196.05$ and $214.60 \mathrm{pg} / \mathrm{ml}$, and the sensitivity was $93.3 \%, 96.7 \%$ and $100.0 \%$, the specificity was $40.0 \%, 50.0 \%$ and $56.7 \%$, respectively.

\section{Conclusion}

Serum VEGF-C,VEGF-D and CXCL-12 levels gradually increased in diabetic nephropathy, which has high value for the early diagnosis and evaluation of disease severity in diabetic nephropathy. These findings suggest that serum VEGF-C,VEGF-D and CXCL-12 levels may be a useful surrogate marker of clinical outcome in DN.

\section{Introduction}

Diabetes mellitus (DM) is a chronic metabolic disease that has seriously affected people's quality of life and health. According to a 2010 survey, the prevalence of prediabetes reached $50.1 \%$, which means that approximately 500 million Chinese adults may have DM, and the prevalence of DM has increased dramatically ${ }^{1}$. DM vascular disease is one of the common complications and is also the main cause of 
death among DM patients. The most common vascular diseases are cardiovascular disease, cerebrovascular disease, and microvascular disease of the kidney, retina and skin. Diabetic nephropathy (DN), a common microvascular complications of DM, has become a major risk factor for end-stage renal disease and a major reason for renal replacement therapy ${ }^{[2]}$. DN is characterized by microalbuminuria, progressive renal impairment, hypertension, edema, and severe renal failure in the late stage.

At present, the main markers examined for the clinical diagnosis of DN are glomerular filtration rate, urinary microalbumin excretion rate, creatinine level, urea nitrogen level and serum cystatin level. Although these markers can be used to effectively evaluate the function of the kidney, they indicate only late changes of kidney function and cannot reflect early structural changes in the kidney ${ }^{2,3}$. Therefore, we need to find new markers that can be used for the early diagnosis of DN.

With the discovery of specific markers of lymphatic endothelial cells, we are aware of the role of lymphangiogenesis in various diseases. Recent studies in mice with DN induced by streptozotocin and a high-fat diet showed that compared with the control group, the experimental group showed a significant increase in the number of lymphatic vessels in the cortex and medulla of the kidney, suggesting that DN may induce lymphangiogenesis of the kidney or at least lymphatic dilatation of the kidney ${ }^{4}$. Vascular endothelial growth factors (VEGF) belong to the platelet-derived growth factor family and play an important role in regulating angiogenesis and lymphangiogenesis. VEGF-C/D is a major member of the VEGF family, which binds to and activates the receptor of vascular endothelial growth factor receptor 3 (VEGFR-3), promotes the proliferation of lymphatic endothelial cells and lymphangiogenesis, and regulates angiogenesis and lymphatic endothelial cell regeneration ${ }^{5,6}$. CXCL-12, also known as stromal cell-derived factor-1 (SDF-1), is a small protein called a cytokine that belongs to the chemokine protein family. CXCL-12 binds to its receptor CXCR4,a novel axis that regulates lymphangiogenesis, which has a strong chemotactic effect on lymphocytes and plays an important role in the development process $\mathrm{s}^{7,8}$.

In this study, we measured serum VEGF-C,VEGF-D and CXCL-12 levels in DN patients at different clinical stages to explore the relationship between lymphangiogenesis and $D N$, further clarify the role of

lymphangiogenesis in DN, and infer whether VEGF-C, VEGF-D and CXCL-12 can be used as markers in the early diagnosis of DN.

\section{Materials And Methods 2.1. Study population}

We adopted a prospective observational study method, and ninety patients with type 2 DM (T2DM) who were hospitalized in our hospital from January 2018 to June 2019 were selected as the study subjects. According to the Mogenson stage, the patients were divided into a normal albuminuria group (UmAlb $<30$ $\mathrm{mg} / 24 \mathrm{~h}, \mathrm{n}=30$ ), microalbuminuria group (UmAlb 30-300 mg/24 h, $\mathrm{n}=30$ ) and massive albuminuria group (UmAlb $>300 \mathrm{mg} / 24 \mathrm{~h}, \mathrm{n}=30$ ), and 30 healthy individuals were enrolled in this study as the healthy control group $(n=30)$. 


\subsection{Inclusion criteria}

The inclusion criteria were (1) age between 18 and 90 years old and(2) type 2 diabetes mellitus, meeting the World Health Organization (WHO) diagnostic and typing criteria for type 2 diabetes in 1999.

\subsection{Exclusion criteria}

The exclusion criteria were as follows: (1) recent occurrence of urinary tract infection or other causes leading to kidney injury and kidney transplantation; (2) diabetic ketoacidosis, hyperosmolar hyperglycemia syndrome and other acute complications; (3) DN combined with tumor disease; (4) pregnant and/or lactating women; (5) DN combined with acute myocardial infarction or cardiac insufficiency patients.; and (6) DN and complicated with autoimmune diseases and inflammation in other parts.

\subsection{Basic data collection}

Questionnaires were developed to collect basic information on patients, such as sex, age, blood pressure (SBP and DBP), fasting blood glucose (FBG) level, triglyceride (TG) level, total cholesterol (TC) level, low density lipoprotein cholesterol (LDL-C) level, high-density lipoprotein cholesterol (HDL-C) level, creatinine ( $\mathrm{Cr}$ ) level, glycosylated hemoglobin (HbA1c) level, urinary microalbumin (UmAlb) level, estimated glomerular filtration rate (eGFR), etc. All the above indicators were based on the results of the first examination after admission.

\subsection{Serum VEGF-C, VEGF-D and CXCL-12 level measurement}

While the patients were in a fasted state, we collected $5 \mathrm{ml}$ of venous blood on the second day after admission with a vacuum anticoagulant tube and centrifuged blood samples for 10 minutes (3000 $\mathrm{r} / \mathrm{min}$ ). The upper serum portion was separated into Eppendorf tubes and stored in a freezer at $-80^{\circ} \mathrm{C}$.

\subsection{Statistical analysis}

All data were analyzed by SPSS 17.0 software. First, the normality test was carried out on measurement data. Measurement data with a normal distribution were expressed as the mean \pm standard deviation. Variance analysis was used for comparison among groups, homogeneity test of variance was carried out by the Levene method, the LSD-t test was used for comparison between groups, and the Tamhane T2 test was used for unequal variance. The count data were analyzed by the chi-square test. Pearson correlation analysis was used to analyze the correlation among the observed indicators. Receiver operating curves (ROCs) were drawn to analyze the value of serum levels of vascular endothelial growth factor-C, vascular endothelial growth factor-D and CXCL-12 in evaluating the severity of DN. $P<0.05$ was statistically significant.

\section{Result}




\subsection{Basic data comparison}

Ninety patients with DN were enrolled in this study, including 60 males and 30 females, aged 37-87 years with an average age of $60.22 \pm 11.04$ years. There were 30 patients in each study group; there were 25 males and 5 females in the healthy control group, aged 23-84 years, with an average age of $60.97 \pm$ 16.52 years. There was no significant difference in sex or age among the groups $(P>0.05)$, which showed that the basic data of each group were balanced and comparable, as shown in Table 1.

Table 1

Basic data of DN patients in different stages and comparison with healthy controls

\begin{tabular}{|c|c|c|c|c|c|}
\hline \multirow[t]{2}{*}{ Group } & \multirow{2}{*}{$\begin{array}{l}\begin{array}{l}\text { No. of } \\
\text { patients }\end{array} \\
(\mathrm{N}=120)\end{array}$} & \multicolumn{2}{|l|}{ Sex } & \multicolumn{2}{|l|}{$\begin{array}{l}\text { Age } \\
\text { (years) }\end{array}$} \\
\hline & & $\begin{array}{l}\text { Male(N = } \\
85)\end{array}$ & $\begin{array}{l}\text { Female(N = } \\
35)\end{array}$ & Range & $x \pm s$ \\
\hline $\begin{array}{l}\text { Normal albuminuria } \\
\text { group }\end{array}$ & 30 & 17 & 13 & $41-83$ & $\begin{array}{l}59.56 \pm \\
11.82\end{array}$ \\
\hline $\begin{array}{l}\text { Microalbuminuria } \\
\text { group }\end{array}$ & 30 & 23 & 7 & $37-75$ & $\begin{array}{l}59.37 \pm \\
9.29\end{array}$ \\
\hline $\begin{array}{l}\text { Massive albuminuria } \\
\text { group }\end{array}$ & 30 & 20 & 10 & $37-87$ & $\begin{array}{l}61.73 \pm \\
12.01\end{array}$ \\
\hline Control group & 30 & 25 & 5 & $23-84$ & $\begin{array}{l}60.97 \pm \\
16.52\end{array}$ \\
\hline$c^{2} / F$-value & & 5.929 & & & 0.24 \\
\hline P-value & & 0.115 & & & 0.868 \\
\hline
\end{tabular}

\subsection{Comparison of serum VEGF-C, VEGF-D and CXCL-12 levels in different groups of DN patients}

One-way ANOVA indicated that the relative expression levels of serum VEGF-C, VEGF-D and CXCL-12 among the massive albuminuria group, microalbuminuria group, normal albuminuria group and control group were significantly different $(P<0.01)$. The LSD-t test was used to compare two groups. Compared with those in the control group, the expression levels of serum VEGF-C, VEGF-D and CXCL-12 in the massive albuminuria group, microalbuminuria group, and normal albuminuria group increased gradually with the progression of $D N$, in the following order: massive albuminuria group $>$ microalbuminuria group $>$ normal albuminuria group $>$ control group; the difference was significant $(P<0.05)$, as shown in Table 2 . 
Table 2

Comparison of serum levels of VEGF-C,VEGF-D and C XCL-12 in different stages of DN

\begin{tabular}{|c|c|c|c|c|}
\hline \multirow[t]{2}{*}{ Group } & $\begin{array}{l}\text { No. of } \\
\text { patients }\end{array}$ & VEGF-C & VEGF-D & CXCL-12 \\
\hline & $(N=120)$ & $\mathrm{pg} / \mathrm{ml}$ & $\mathrm{pg} / \mathrm{ml}$ & $\mathrm{pg} / \mathrm{ml}$ \\
\hline Normal albuminuria group & 30 & $\begin{array}{l}239.54 \pm \\
58.18\end{array}$ & $\begin{array}{l}265.18 \pm \\
65.22\end{array}$ & $\begin{array}{l}625.10 \pm \\
172.17\end{array}$ \\
\hline Microalbuminuria group & 30 & $\begin{array}{l}280.00 \pm \\
62.78\end{array}$ & $\begin{array}{l}321.02 \pm \\
68.64\end{array}$ & $\begin{array}{l}727.87 \pm \\
169.97\end{array}$ \\
\hline $\begin{array}{l}\text { Massive albuminuria group } \\
\mathrm{C}\end{array}$ & 30 & $\begin{array}{l}303.46 \pm \\
62.34\end{array}$ & $\begin{array}{l}359.44 \pm \\
72.86\end{array}$ & $\begin{array}{l}823.82 \pm \\
172.46\end{array}$ \\
\hline Control group & 30 & $\begin{array}{l}201.75 \pm \\
66.10\end{array}$ & $\begin{array}{l}212.62 \pm \\
64.61\end{array}$ & $\begin{array}{l}510.70 \pm \\
154.89\end{array}$ \\
\hline F-value & & 15.51 & 26.858 & 19.38 \\
\hline P-value & & $<0.001$ & $<0.001$ & $<0.001$ \\
\hline
\end{tabular}

\subsection{The relationship between serum VEGF-C, VEGF-D and CXCL-12 levels and major clinical indicators of DN}

The correlation analysis showed that serum levels of VEGF-C, VEGF-D and CXCL-12 had no significant correlation with age, sex, systolic blood pressure, diastolic blood pressure, fasting blood lucose level, triglyceride level and total cholesterol level in DN patients $(P>0.05)$. Serum levels of VEGF-C were significantly negatively correlated with eGFR $(-0.366, P<0.01)$ and significantly positively correlated with UmAlb and Cr levels $(0.357,0.283, P<0.01$, respectively); serum levels of VEGF-D were significantly negatively correlated with eGFR $(-0.478, P<0.01)$, and significantly positively correlated with UmAlb and Cr levels $(0.479,0.43, P<0.01$, respectively); finally, serum levels of CXCL-12 were significantly negatively correlated with eGFR $(-0.486, P<0.01)$ and significantly positively correlated with UmAlb and Cr levels $(0.396,0.431, P<0.01$, respectively), as shown in Table 3. 
Table 3

Relationship between serum VEGF-C, VEGF-D and CXCL-12levels and clinical indicators of DN

\begin{tabular}{|c|c|c|c|c|c|c|}
\hline \multirow[t]{2}{*}{ Clinical parameters } & \multicolumn{2}{|c|}{ VEGF-C } & \multicolumn{2}{|c|}{ VEGF-D } & \multicolumn{2}{|c|}{ CXCL-12 } \\
\hline & $\mathbf{r}$ & $\mathbf{P}$ & $\mathbf{r}$ & $\mathbf{P}$ & $\mathbf{r}$ & $\mathbf{P}$ \\
\hline Age (years) & -0.062 & $>0.05$ & 0.016 & $>0.05$ & 0.122 & $>0.05$ \\
\hline Sex(male/female) & 0.057 & $>0.05$ & 0.140 & $>0.05^{*}$ & -0.176 & $>0.05$ \\
\hline $\mathrm{SBP}(\mathrm{mmHg})$ & 0.061 & $>0.05$ & 0.144 & $>0.05$ & 0.294 & $<0.05$ \\
\hline $\mathrm{DBP}(\mathrm{mmHg})$ & -0.085 & $>0.05$ & 0.103 & $>0.05$ & 0.056 & $>0.05$ \\
\hline Cr(umol/L) & 0.283 & $<0.01$ & 0.436 & $<0.01$ & 0.413 & $<0.01$ \\
\hline $\operatorname{eGFR}\left(\mathrm{ml} / \mathrm{min} / 1.73 \mathrm{~m}^{2}\right)$ & -0.366 & $<0.01$ & -0.478 & $<0.01$ & -0.486 & $<0.01$ \\
\hline $\mathrm{FBS}(\mathrm{mmol} / \mathrm{L})$ & 0.139 & $>0.05$ & 0.225 & $>0.05$ & 0.141 & $>0.05$ \\
\hline $\mathrm{TG}(\mathrm{mmol} / \mathrm{L})$ & 0.115 & $>0.05$ & 0.140 & $>0.05$ & -0.032 & $>0.05$ \\
\hline $\mathrm{TC}(\mathrm{mmol} / \mathrm{L})$ & -0.107 & $>0.05$ & -0.013 & $>0.05$ & 0.140 & $>0.05$ \\
\hline LDL-C(mmol/L) & -0.162 & $>0.05$ & -0.068 & $>0.05$ & 0.161 & $>0.05$ \\
\hline mAlb(mg/24h) & 0.194 & $>0.05$ & 0.367 & $<0.01^{*}$ & 0.401 & $<0.01$ \\
\hline
\end{tabular}

\subsection{Diagnostic value of serum levels of VEGF-C, VEGF-D and CXCL-12 in DN}

ROC curve analysis showed that the areas under the ROC curve (AUCs) in the normal albuminuria group, microalbuminuria group, and massive albuminuria group were $0.668,0.799$ and 0.850 . When the cutoff value were $152.40,196.05$ and $214.60 \mathrm{pg} / \mathrm{ml}$, the sensitivity was $93.3 \%, 96.7 \%$ and $100.0 \%$, and the specificity was $40.0 \%, 50.0 \%$ and $56.7 \%$, respectively. The serum VEGF-D and CXCL-12 levels used to assess the area under the ROC curve in the massive albuminuria group, microalbuminuria group, and normal albuminuria group were higher than the VEGF-C level, which indicated that serum levels of VEGFC, VEGF-D and CXCL-12 had a certain value for the early diagnosis and assessment of disease of severity of DN, as shown in Figs. 1, 2, and 3; Tables 4, 5, and 6. 
Table 4

Value of serum levels of VEGF-C in assessing severity of DN

\begin{tabular}{|llllllll|}
\hline $\begin{array}{l}\text { VEGF- } \\
\text { C }\end{array}$ & AUG & $\mathbf{s}^{2} \mathbf{x}$ & $\begin{array}{l}\text { P- } \\
\text { value }\end{array}$ & $95 \% \mathrm{Cl}$ & $\begin{array}{l}\text { Cut-off } \\
\text { value }\end{array}$ & $\begin{array}{l}\text { Sensitivity } \\
(\%)\end{array}$ & $\begin{array}{l}\text { Specificity } \\
(\%)\end{array}$ \\
\hline $\begin{array}{l}\text { Group } \\
\text { A }\end{array}$ & 0.668 & 0.070 & 0.025 & $\begin{array}{l}0.531- \\
0.805\end{array}$ & 152.40 & 93.3 & 40.0 \\
\hline $\begin{array}{l}\text { Group } \\
\text { B }\end{array}$ & 0.799 & 0.057 & 0.000 & $\begin{array}{l}0.678- \\
0.902\end{array}$ & 196.05 & 96.7 & 50.0 \\
\hline $\begin{array}{l}\text { Group } \\
\text { C }\end{array}$ & 0.850 & 0.048 & 0.000 & $\begin{array}{l}0.756- \\
0.944\end{array}$ & 214.60 & 100.0 & 56.7 \\
\hline
\end{tabular}

Table 5

Value of serum levels of VEGF-D in assessing severity of DN

\begin{tabular}{|llllllll|}
\hline VEGF-D & AUG & $\mathbf{s}^{\prime} \mathbf{x}$ & $\begin{array}{l}\text { P- } \\
\text { value }\end{array}$ & $95 \% \mathrm{Cl}$ & $\begin{array}{l}\text { Cut-off } \\
\text { value }\end{array}$ & $\begin{array}{l}\text { Sensitivity } \\
(\%)\end{array}$ & $\begin{array}{l}\text { Specificity } \\
(\%)\end{array}$ \\
\hline $\begin{array}{l}\text { Group } \\
\text { A }\end{array}$ & 0.718 & 0.067 & 0.004 & $\begin{array}{l}0.587- \\
0.848\end{array}$ & 240.90 & 66.7 & 73.3 \\
$\begin{array}{l}\text { Group } \\
\text { B }\end{array}$ & 0.873 & 0.046 & 0.000 & $\begin{array}{l}0.783- \\
0.963\end{array}$ & 275.05 & 86.7 & 83.3 \\
$\begin{array}{l}\text { Group } \\
\text { C }\end{array}$ & 0.931 & 0.030 & 0.000 & $\begin{array}{l}0.872- \\
0.991\end{array}$ & 289.15 & 83.3 & 90.0 \\
\hline
\end{tabular}

Table 6

Value of serum levels of CXCL-12 in assessing severity of DN

\begin{tabular}{|llllllll|}
\hline $\begin{array}{l}\text { CXCL- } \\
12\end{array}$ & AUG & s'x $^{\prime}$ & $\begin{array}{l}\text { P- } \\
\text { value }\end{array}$ & $95 \% \mathrm{Cl}$ & $\begin{array}{l}\text { Cut-off } \\
\text { value }\end{array}$ & $\begin{array}{l}\text { Sensitivity } \\
(\%)\end{array}$ & $\begin{array}{l}\text { Specificity } \\
(\%)\end{array}$ \\
\hline $\begin{array}{l}\text { Group } \\
\text { A }\end{array}$ & 0.687 & 0.068 & 0.013 & $\begin{array}{l}0.554- \\
0.820\end{array}$ & 592.30 & 60.0 & 70.0 \\
$\begin{array}{l}\text { Group } \\
\text { B }\end{array}$ & 0.816 & 0.054 & 0.000 & $\begin{array}{l}0.710- \\
0.921\end{array}$ & 660.85 & 70.0 & 83.3 \\
$\begin{array}{l}\text { Group } \\
\text { C }\end{array}$ & 0.903 & 0.038 & 0.000 & $\begin{array}{l}0.829- \\
0.977\end{array}$ & 724.55 & 70.0 & 96.7 \\
\hline
\end{tabular}

\section{Discussion}

The lymphatic system is an important auxiliary system of tissue fluid reflux, which plays an important role in maintaining the dynamic balance of tissue fluid, lipid absorption, immune monitoring and other physiological processes. In many pathological conditions (such as inflammatory reactions, tissue wound repair, organ transplantation, and tumors), lymphatic vessel formation can be reactivated ${ }^{9,10}$. At present, research on lymphangiogenesis both domestically and internationally is mainly concentrated in the field 
of cancer, and the mechanism of lymphangiogenesis in DN is not clear. It is well known that inflammation is considered to be an important factor in lymphangiogenesis, and the involvement of inflammatory factors (such as interleukin-1 and tumor necrosis factor alpha) and macrophages can increase the production of vascular endothelial factors, thus promoting lymphangiogenesis ${ }^{11,12}$. In recent reports on human kidney diseases, we found that lymphangiogenesis is affected by the duration of inflammation and fibrosis progression, rather than acute inflammation. As a type of chronic interstitial inflammation, DN is characterized by mesangial dilatation, podocyte loss, glomerular proliferation, glomerular basement membrane thickening and tubular epithelial cell dysfunction, which leads to glomerular capillary occlusion; therefore, lymphatic vessel formation is considered a kind of renal edema and hypertension compensation response $e^{4,13,14}$.

DN is a serious complication of DM and initially manifests as microalbuminuria. Persistent diabetesrelated metabolic and hemodynamic disorders can lead to inflammatory changes in the kidney, and promote the process from injury to repair of the kidney, leading to renal fibrosis, especially after stages III and IV, and the degree of renal fibrosis is more significant ${ }^{15,16}$. Many studies have shown that renal fibrosis is accompanied by lymphangiogenesis. One study induced renal fibrosis by constructing a unilateral ureteral obstruction model in mice and found that the degree of renal lymphangiogenesis was positively correlated with renal fibrosis ${ }^{17}$. To understand the relationship between lymphangiogenesis and renal fibrosis, another study used unilateral ureteral obstruction in rats to analyze the relationship between inflammation, fibrosis, lymphangiogenesis and growth factor expression; it was found that transforming growth factor- $\beta 1$ (TGF- $\beta 1$ ) and VEGF-C were present in renal tubular epithelial cells and monocytes, where their levels gradually increased and reached a peak at 14 days after ureteral obstruction ${ }^{18}$. Sakamoto I et al, through pathological examination of 124 renal biopsy specimens, found an increase in lymphatic vessel number in patients with tubulointerstitial disease compared with the control group and that this was related to the degree of tissue damage; moreover, the correlation with the fibrotic area was stronger than that with the inflamed area. In addition, compared with other renal diseases, lymphangiogenesis in DN patients was more significant ${ }^{19}$. Therefore, lymphangiogenesis is a common feature of tubulointerstitial fibrosis.

The advantages and disadvantages of lymphangiogenesis in DN are still controversial. Lymphatic vessels, an important regulator of fluid balance, immune cell transport and immune recognition, play an important role in many diseases. DN is the main cause of end-stage renal disease worldwide. Hyperglycemia-induced oxidative stress and inflammation play an important role in the occurrence and development of DN. Lymphangiogenesis is an important part of the inflammatory process of tissues and organs. Many studies have shown that the dilated lymphatic system is necessary to resolve inflammation, and lymphatic vessels play an important role in fluid clearance and immune cell transport, thus achieving the effect of reducing or alleviating inflammation ${ }^{20,21}$. However, recent studies have shown that lymphangiogenesis is not necessarily beneficial to the progression of DN. Functional lymphatics play an important role in the process of body fluid balance and immune monitoring, but disordered expansion of lymphatics can lead to the failure of immune cell clearance, which leads to 
chronic inflammation. Recent studies have found that in DN mice, selective inhibition of VEGFR-3 to inhibit lymphatic proliferation could reduce the serum cholesterol level, free fatty acids and proteinuria, thus decreasing inflammation and oxidative stress in the kidney and alleviating renal fibrosis ${ }^{22}$. Another study also questioned the involvement of lymphatic function DN. With the development of chronic inflammation in $\mathrm{DN}$, the expression of various inflammatory factors was not balanced, resulting in the excessive growth of lymphatic vessels, which eventually led to structural incompleteness and dysfunction. Studies have shown that by reducing renal lipid toxicity, renal lymphatic dysfunction can be alleviated in DN, thereby alleviating the degree of renal inflammation and fibrosis ${ }^{23}$.

\section{Conclusion}

The results of this study showed that the serum levels of VEGF-C, VEGF-D and CXCL-12 were closely related to DN. With the development of DN, the expression levels of serum VEGF-C, VEGF-D and CXCL-12 increased gradually, which is also consistent with the findings of many studies, proving that lymphangiogenesis accompanies the development of DN and is positively correlated with the severity of the disease. ROC curve analysis showed that the serum levels of VEGF-C, VEGF-D and CXCL-12 had certain value in the early diagnosis of $\mathrm{DN}$, and could at least be used to predict the progression of the disease. At present, there is still controversy about whether lymphangiogenesis is good or bad for $\mathrm{DN}$, but many studies have shown that inhibiting lymphangiogenesis can alleviate inflammation and fibrosis of DN to a certain extent, which provides us with new ideas and perspectives for the treatment in DN, but further studies and clinical trials are needed to prove this.

\section{Abbreviations}

UmAlb: Urine Microalbumin; VEGF-C: vascular endothelial growth factor-C; VEGF-D: vascular endothelial growth factor-D ; CXCL-12:chemokine ligand 12; AUC-ROCs: areas under the receiver operating characteristic curve; DM: Diabetes mellitus; DN: Diabetic nephropathy; VEGF: Vascular endothelial growth factors; VEGFR-3: vascular endothelial growth factor receptor 3; SDF-1: stromal cell-derived factor-1; FBG: fasting blood glucose; TG: triglyceride; TC: total cholesterol; LDL-C: low density lipoprotein cholesterol; HDL-C: high-density lipoprotein cholesterol; Cr: creatinine; HbA1c:glycosylated hemoglobin; eGFR: estimated glomerular filtration rate; ROCs: Receiver operating curves; TGF- $\beta 1$ : transforming growth factor$\beta 1$.

\section{Declarations}

\section{Acknowledgements}

We thank all the patients who participated in this study.

\section{Funding}

The project was funded by Natural Science Foundation of Jiangxi Province (NO. S2020ZRZDB0203). 


\section{Authors' contributions}

Qingshan Tian, Zhichao Yang, Lianfei Li, Yun Kong, Hongwen Zhu and Yiheng Yang collected the data, Qingshan Tian , Zhichao Yang, Zhenzhong Zheng and Hao Wu analyzed the data. Qingshan Tian and Zhichao Yang wrote the paper.

\section{Availability of data and materials}

Data can be obtained by contacting the first author: Qingshan Tian; e-mail: tqs576342580@sina.com.

\section{Ethics approval and consent to participate}

This trial was approved by the First Affiliated Hospital of Nanchang University Ethics Committee. Informed consent was obtained from all participants.

\section{Consent for publication}

Informed consent for publication was obtained from all participants.

\section{Competing interests}

The authors have no financial or commercial conflicts of interest.

\section{References}

1. Wang L, Gao P, Zhang M, et al. Prevalence and Ethnic Pattern of Diabetes and Prediabetes in China in 2013. Jama. 2017;317(24):2515-2523.

2. Tziomalos K, Athyros VG. Diabetic Nephropathy: New Risk Factors and Improvements in Diagnosis. The review of diabetic studies: RDS. 2015;12(1-2):110-118.

3. Campion CG, Sanchez-Ferras O, Batchu SN. Potential Role of Serum and Urinary Biomarkers in Diagnosis and Prognosis of Diabetic Nephropathy. Canadian journal of kidney health and disease. 2017;4:2054358117705371.

4. Uchiyama T, Takata S, Ishikawa H, Sawa Y. Altered dynamics in the renal lymphatic circulation of type 1 and type 2 diabetic mice. Acta histochemica et cytochemica. 2013;46(2):97-104.

5. García-Caballero M, Blacher S, Paupert J, Quesada AR, Medina MA, Noël A. Novel application assigned to toluquinol: inhibition of lymphangiogenesis by interfering with VEGF-C/VEGFR-3 signalling pathway. British journal of pharmacology. 2016;173(12):1966-1987.

6. Shibuya M. Vascular endothelial growth factor and its receptor system: physiological functions in angiogenesis and pathological roles in various diseases. Journal of biochemistry. 2013;153(1):1319.

7. Cha YR, Fujita M, Butler $M$, et al. Chemokine signaling directs trunk lymphatic network formation along the preexisting blood vasculature. Developmental cell. 2012;22(4):824-836. 
8. Zhuo W, Jia L, Song N, et al. The CXCL12-CXCR4 chemokine pathway: a novel axis regulates lymphangiogenesis. Clinical cancer research : an official journal of the American Association for Cancer Research. 2012;18(19):5387-5398.

9. Vaahtomeri K, Karaman S, Mäkinen T, Alitalo K. Lymphangiogenesis guidance by paracrine and pericellular factors. Genes \& development. 2017;31(16):1615-1634.

10. Vuorio T, Tirronen A, Ylä-Herttuala S. Cardiac Lymphatics - A New Avenue for Therapeutics? Trends in endocrinology and metabolism: TEM. 2017;28(4):285-296.

11. Kerjaschki D, Huttary N, Raab I, et al. Lymphatic endothelial progenitor cells contribute to de novo lymphangiogenesis in human renal transplants. Nature medicine. 2006;12(2):230-234.

12. Skobe M, Hawighorst T, Jackson DG, et al. Induction of tumor lymphangiogenesis by VEGF-C promotes breast cancer metastasis. Nature medicine. 2001;7(2):192-198.

13. Mauer SM, Steffes MW, Ellis EN, Sutherland DE, Brown DM, Goetz FC. Structural-functional relationships in diabetic nephropathy. The Journal of clinical investigation. 1984;74(4):1143-1155.

14. Mason RM, Wahab NA. Extracellular matrix metabolism in diabetic nephropathy. Journal of the American Society of Nephrology : JASN. 2003;14(5):1358-1373.

15. Malik S, Suchal K, Khan SI, et al. Apigenin ameliorates streptozotocin-induced diabetic nephropathy in rats via MAPK-NF-KB-TNF-a and TGF-B1-MAPK-fibronectin pathways. American journal of physiology Renal physiology. 2017;313(2):F414-f422.

16. Zheng S, Powell DW, Zheng F, Kantharidis P, Gnudi L. Diabetic Nephropathy: Proteinuria, Inflammation, and Fibrosis. Journal of diabetes research. 2016;2016:5241549.

17. Lee AS, Lee JE, Jung YJ, et al. Vascular endothelial growth factor-C and -D are involved in lymphangiogenesis in mouse unilateral ureteral obstruction. Kidney international. 2013;83(1):50-62.

18. Suzuki $Y$, Ito $Y$, Mizuno $M$, et al. Transforming growth factor- $\beta$ induces vascular endothelial growth factor-C expression leading to lymphangiogenesis in rat unilateral ureteral obstruction. Kidney international. 2012;81(9):865-879.

19. Sakamoto I, Ito Y, Mizuno M, et al. Lymphatic vessels develop during tubulointerstitial fibrosis. Kidney international. 2009;75(8):828-838.

20. Aebischer $D$, lolyeva M, Halin C. The inflammatory response of lymphatic endothelium. Angiogenesis. 2014;17(2):383-393.

21. Abouelkheir GR, Upchurch BD, Rutkowski JM. Lymphangiogenesis: fuel, smoke, or extinguisher of inflammation's fire? Experimental biology and medicine (Maywood, NJ). 2017;242(8):884-895.

22. Hwang SD, Song JH, Kim Y, et al. Inhibition of lymphatic proliferation by the selective VEGFR-3 inhibitor SAR131675 ameliorates diabetic nephropathy in $\mathrm{db} / \mathrm{db}$ mice. Cell death \& disease. 2019;10(3):219.

23. Kim Y, Hwang SD, Lim JH, et al. Attenuated Lymphatic Proliferation Ameliorates Diabetic Nephropathy and High-Fat Diet-Induced Renal Lipotoxicity. Scientific reports. 2019;9(1):1994. 
Figures

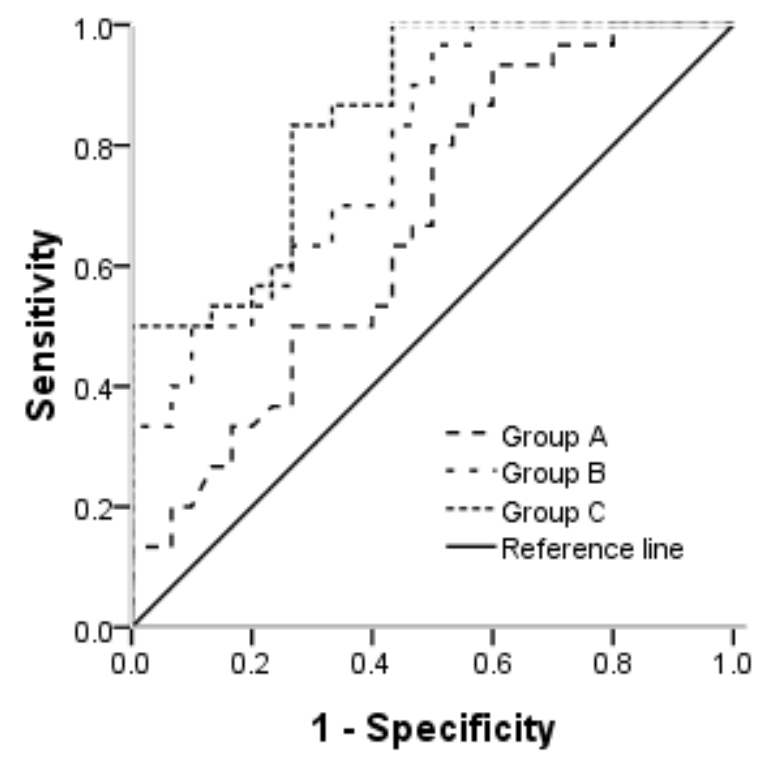

\section{Figure 1}

The ROC curves of serum VEGF-C in different groups for diagnosis of DN.

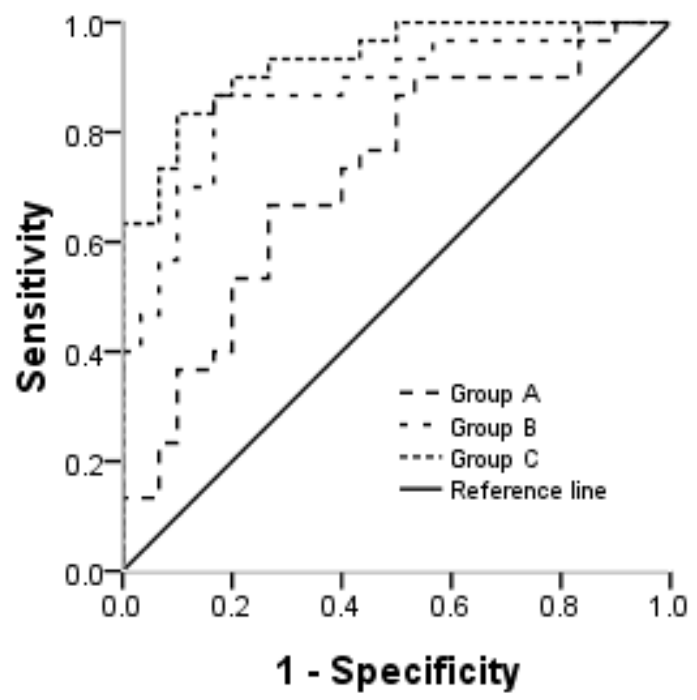

Figure 2

The ROC curves of serum VEGF-D in different groups for diagnosis of DN. 


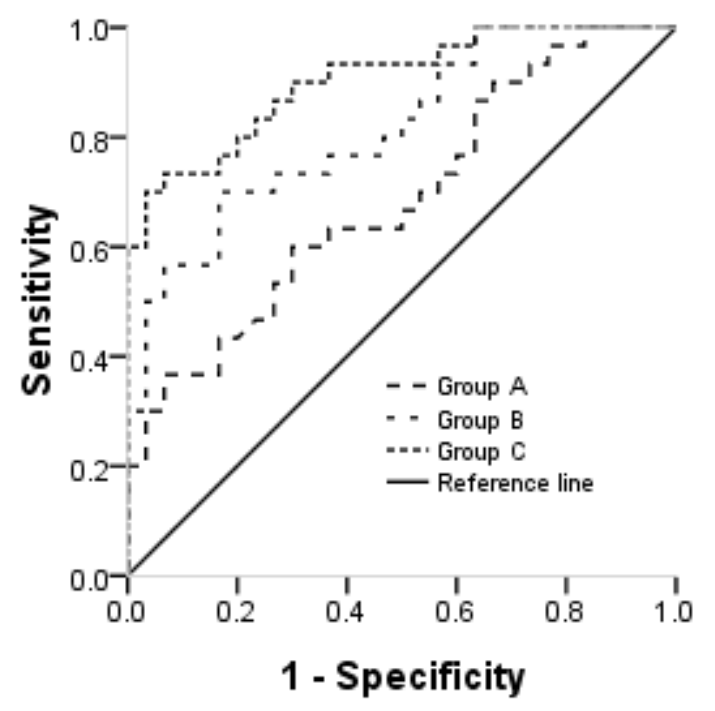

Figure 3

The ROC curves of serum CXCL-12 in different groups for diagnosis of DN. 